\title{
Historical, architectonic and structural investigations of the Bell Tower of Santa Maria del Carmine Church
}

Received (in revised form): 30th March, 2007

\section{Francesca Ceroni}

is Assistant Professor in Structural Engineering at the University of Sannio, Benevento, Italy. Her main research activities regard steel-concrete bond behaviour, composite materials for retrofitting of existing concrete and masonry structures and nonlinear behaviour of masonry structures with experimental and theoretical applications. She is a member of the fib task groups 4.1 on 'Serviceability models' and 9.3 on 'FRP reinforcement for concrete structures'.

\section{Marisa Pecce}

is Full Professor of Structural Engineering at the University of Sannio, Benevento, Italy. She is interested in theoretical-experimental research in the fields of nonlinear and cyclic behaviour of reinforced concrete elements, steel-concrete composite structures, steel-concrete bond behaviour, high-performance concrete, composite materials for new structures, and retrofitting and seismic engineering. She is a member of the fib task groups 4.1 on 'Serviceability models' and 9.3 on 'FRP reinforcement for concrete structures' and is vice-president of American Concrete Institute (ACl) Italy Chapter.

\section{Simona Voto}

is an architect specialising in architectural restoration and is a PhD student in the Engineering Faculty of the University Federico II, Napoli, Italy. Her main area of research is the utilisation of innovative technologies in the field of structure restoration with particular focus on the historical masonry buildings.

Correspondence: Francesca Ceroni, Engineering Department, University of Sannio, Piazza Roma, 21 - 82100, Benevento, Italy; Tel: + 39824 305575; Fax: + 39824 325246; E-mail: ceroni@unisannio.it

\begin{abstract}
Detailed historical and architectonical investigation was performed on the Bell Tower of Santa Maria del Carmine Church in Naples. Geometrical and material surveys and destructive and nondestructive tests were performed in situ to evaluate the level of damage, the sequence of changes in the structures and the stress distribution due to static loads. Experimental dynamic characterisation of the Bell Tower was conducted and the environmental effects of vibrations due to wind, traffic and the ringing of the Towers' bells were considered. Linear static and dynamic analyses were developed to compare experimental with analytical results in terms of stress level for vertical loads and dynamic behaviour. Journal of Building Appraisal (2007) 3, 155-179. doi:10.1057/palgrave.jba.2950068
\end{abstract}

\section{Keywords:}

historical masonry buildings, geometrical and material surveys, in situ testing, material properties, static and dynamic behaviour

\section{INTRODUCTION}

The restoration of an historical building requires technical and historical investigation in order to assess its main architectural features and the effects superimposed by its history. A detailed geometrical survey makes possible the detection of characteristic features such as alignments, wall configurations, microcracks and construction details. The study of the structure through historical, archival and bibliographical documentation is useful to 
characterise, analyse and record the origin of the structure and the vicissitudes during its history. In addition, the variability of other important parameters such as wall texture, quality of connections, nature and dimensions of its component elements (ie disposition and dimensions of blocks), mechanical properties of the various constituent materials (ie quality and thickness of mortar) and of their assembling has to be taken into account and this might lead to the need for detailed in situ testing (Binda et al., 2000). The original mechanical properties of the construction materials, often dependent on the geographical location of a building (ie same natural stone types can have different properties if carved from different quarries), are often modified by the age of the building and environmental effects over time. Historical investigation can also help to clarify the reasons for earlier structural repairs and the overall evolution of the building as well as of the surrounding buildings that might have an impact upon the structure being studied.

\section{SCHEME OF INVESTIGATIONS}

The investigations to assess the structural behaviour of a building, and where required, to design reinforcing solutions may be divided into different categories as detailed in Table 1 . A correct assessment of the structural behaviour of historical masonry buildings appears to be strongly associated with the utilisation of nondestructive testing (Carpinteri and Bocca, 1991; Binda et al., 2000), but without a comprehensive historical survey and architectural analysis the results would be significantly less useful or reliable. To understand the role of the different investigation categories detailed in Table 1, the following sections summarise the research that has been applied to the Bell Tower of the Santa Maria del Carmine Church in Naples, Italy.

\section{HISTORICAL SURVEY}

The research of historical information has been made by consulting books of history and literature as well as of architecture and by studying images of the building in paintings and photographs. Particularly, attention was given in understanding the evolution and various phases of construction that influenced the materials and techniques used.

Furthermore, the development over time of surrounding buildings that could have an impact on the Bell Tower was also considered.

The Santa Maria del Carmine Church complex (Figure 1) is located at the extreme periphery of the ancient city of Naples in Italy. The Bell Tower is now $68 \mathrm{~m}$ tall (with an

Table I: Categories of investigation

\begin{tabular}{|c|c|c|}
\hline $\begin{array}{l}\text { Investigation } \\
\text { category }\end{array}$ & Objective & Activity \\
\hline Historical & $\begin{array}{l}\text { Assessment and definition of construction } \\
\text { and its modifications }\end{array}$ & $\begin{array}{l}\text { Research in the Archives, Building City Repository, } \\
\text { SuperIntendence, Civil Construction Authority, etc. }\end{array}$ \\
\hline Architectural & $\begin{array}{l}\text { Geometry of nonstructural elements to } \\
\text { determine their weight }\end{array}$ & $\begin{array}{l}\text { Geometrical survey, coating survey and historically } \\
\text { valuable elements survey }\end{array}$ \\
\hline \multirow[t]{3}{*}{ Structural } & $\begin{array}{l}\text { Geometry of structural elements } \\
\text { Materials of structural elements } \\
\text { Conditions of degradation of structural } \\
\text { elements }\end{array}$ & $\begin{array}{l}\text { Geometrical survey } \\
\text { Survey of materials } \\
\text { Survey of cracks and decay }\end{array}$ \\
\hline & Mechanical properties of structural materials & $\begin{array}{l}\text { Destructive and non-destructive experimental tests } \\
\text { in situ }\end{array}$ \\
\hline & $\begin{array}{l}\text { Stress distribution in structural elements } \\
\text { Identification of the global structural } \\
\text { behaviour of the structure }\end{array}$ & $\begin{array}{l}\text { Experimental tests in situ } \\
\text { Dynamic experimental test in situ }\end{array}$ \\
\hline
\end{tabular}




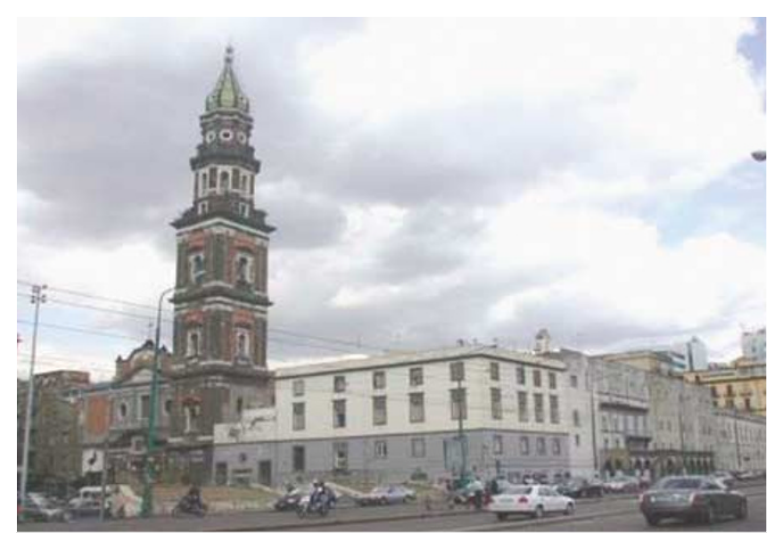

Figure I: The complex of Santa Maria of Carmine

additional cross of $4.5 \mathrm{~m}$ ) and consists of six storeys plus a basement. The first historical citation of the Bell Tower is in 'Chronistoria del Real Convento del Carmine Maggiore' (Moscarella et al., 1589-1825), which reported that during an earthquake in 1456 the upper portion of the building collapsed, which resulted in demolition of the remaining parts. Construction of a new Bell Tower was initiated in 1458 but it was not until 1615 that significant further building works were resumed. Following the plans of architect Giovan Giacomo di Conforto, three storeys were built above the ancient base (Filangieri, 1885). Works were then interrupted in 1620 and were resumed again two years later by the Dominican monk and architect Giuseppe Donzelli (also known as Fra' Nuvolo) who completed the Bell Tower with an octagonal cell and pyramidal cusp and closing the top with a characteristic 'pear' shape covered with polychromatic glazed tiles. This period of construction was completed by 1631 .

The 17 th century structure rises out of the 14 th century basement of the old Tower where remainders of the original configuration can still be seen. At present, the first two levels are surrounded by adjacent buildings (the church of Santa Maria del Carmine, the congregation building and the monastery, see Figures 1-3), while the upper storeys are free on each side.

In the past the Tower has been subjected to several changes that have contributed to make it very discontinuous both architectonically and structurally. For example, the layout along the height of the Tower changes from a rectangular cross-section, up to the $41.4 \mathrm{~m}$ level, to an octagonal cross-section layout until $57 \mathrm{~m}$, where the pear-shaped dome begins and covers the top of the Tower.

The Bell Tower is not an isolated structure but rather is part of a building system (Figures 2 and 3) that has experienced architectural and structural modifications over the centuries. The Bell Tower is joined between two other buildings, the Church of the Carmine the Major on the northern side, up to a height of about $19 \mathrm{~m}$, and the Congregation of 'S. Maria dell'Angelo' on the southern side, up to a height of about $16 \mathrm{~m}$, as shown in Figure 1. The western side of the Tower faces the main square and is completely open while the eastern side borders the cloister of the Church. Historical surveys revealed that the Congregation was built after the Bell Tower and without any structural connection with the pre-existing walls. Although the church and the Bell Tower are now joined, originally they were separated as depicted in an engraving by Petrini (Celano and Chiarini, 1974) and in Antonio Joli's painting (National Motor Museum, Beulieu, England) dating, respectively, from the 18th and 17th centuries, and which 
Ceroni, Pecce and Voto

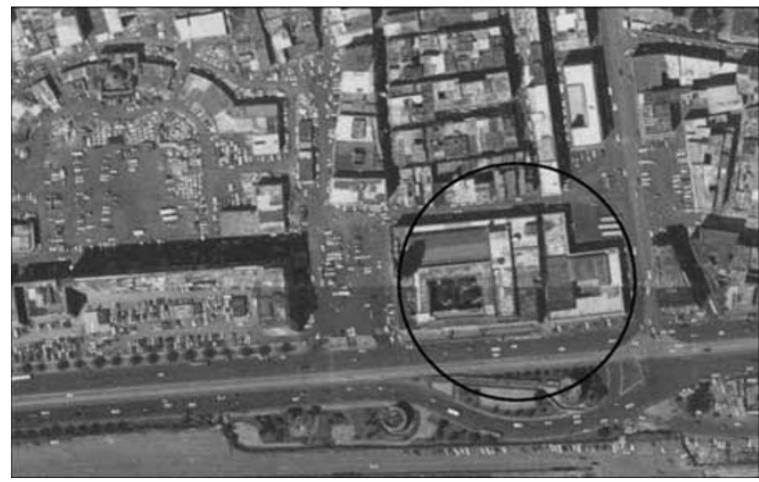

Figure 2: Aerial view of the complex

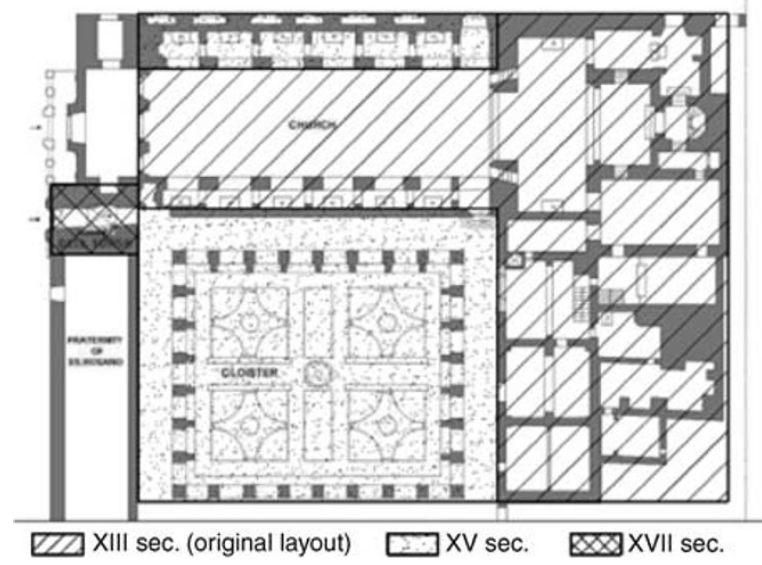

Figure 3: The overall layout of the Santa Maria del Carmine complex

clearly show a narrow space between the two buildings. In both representations, it is possible to see also two windows similar to the ones in the upper storeys on the side that is nowadays completely sheltered.

At the end of the 18th century, the church was modified considerably (Filangieri, 1885; Quagliarella, 1932) and included changing of the original Renaissance-styled façade to the current baroque-styled façade as well as moving the original entry to the front; this is the reason why the side of the Bell Tower adjacent to the body of the church is hidden as the pre-existing windows were closed off and the space in between was filled with different materials to enhance the homogeneity of the whole complex. On the inside of the first level of the Bell Tower, traces of an opening that very probably corresponds to the pre-existing window can be seen.

The degree of the interaction between the three structures (Bell Tower, church and congregation), according to the modifications over the centuries, was verified further through the survey of materials, geometry and dynamic characterisation of the whole structure. An understanding of the interactions between the three structures is paramount in establishing the constraints of the surrounding buildings on the Bell Tower to design a structural model and to evaluate reciprocal actions under static and seismic loads. 


\section{ARCHITECTONICAL ANALYSIS}

The study of structures requires an in-depth knowledge of their geometry, as well as of the materials used, and is particularly important for monumental masonry buildings that can have a very complex behaviour depending on several parameters. A topographicphotogrammometric survey was conducted on the Bell Tower and generated a graphical representation with 12 planar views, four vertical views and eight cross-sections. In particular, the survey helped to determine wall thickness at the different levels (which varied from 4 to $1 \mathrm{~m}$ ), the thickness and configuration of the floors (wooden floors, masonry vaults and reinforced concrete (RC) slabs), the horizontal and vertical layout of the stairs, the horizontal and vertical interactions with surrounding structures and the location of the relative openings, and the positions of steel bars and strands. Figures 4-8 show, respectively, the front prospect, a longitudinal section and three planar views at the ground level, 19 and $40 \mathrm{~m}$. Up to the $41.4 \mathrm{~m}$ level the Tower has a rectangular layout, although this appears as rather irregular over in the first metres because of the uncertainty in the definition of contours at the basement level of the Tower, the church and the congregation. Above $41.4 \mathrm{~m}$, the plan assumes an octagonal shape with decreasing wall thickness and a greater number of openings.

\section{STRUCTURAL ANALYSIS}

\section{The material survey}

As introduced in the previous paragraph, the geometrical survey allowed definition of the geometry of both structural and architectonic decorative elements. The structural behaviour of masonry buildings is dependent not only on the geometry of the elements but also on the texture and composition of the walls and on the mechanical properties of the constituent materials including the masonry blocks as well as the mortar and the way they are assembled together. For faced masonry walls, the typology of filling materials and the level of connection between the external walls are further parameters that can affect structural behaviour and therefore must also be investigated.

The materials survey was made by a preliminary visual analysis to define the variability of materials and texture in the Bell Tower. Surface plaster was removed at various internal points to identify masonry texture (frame with dimensions about $50 \times 50 \mathrm{~cm}$ ). The examination of the wall textures and the materials found inside the Bell Tower evidenced that they were typical for typology and construction techniques of the Neapolitan area. This survey also helped to identify the different periods of construction and where these phases of construction overlapped.

The analysis revealed that the Tower comprises faced masonry of tuff up to $41.4 \mathrm{~m}$ with an external basement of piperno for the first $7.5 \mathrm{~m}$ and an internal covering in peperino, while the walls of the upper levels are made of full clay bricks masonry but with some openings closed off with tuff block curtains. Tuff is a natural volcanic stone typical of the Naples area and has a characteristic yellow colour and is used widely as a construction material in Southern Italy due to its excellent mechanical properties under compression and low weight, while piperno and peperino are volcanic lapideous dark stones generally used as internal and external wall coverings. The peperino covering the backup tuff wall (Figure 9) is constructed of well-squared and aligned rectangular-shaped stones approximately $20 \mathrm{~cm}$ thick and with thin mortar joints of $1.5 \mathrm{~cm}$. This texture is typical of the 14th century base structure architecture and confirms the hypothesis that the 17th century structure was built atop the 14th century buildings. 


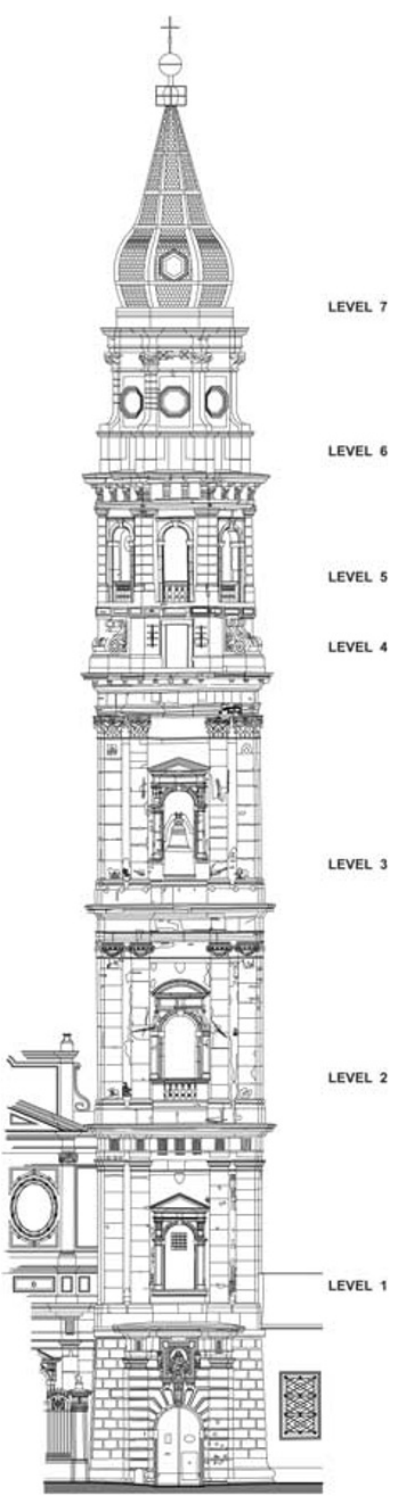

Figure 4: Front prospect

The levels having a rectangular layout $(0-41.4 \mathrm{~m})$ and built with a faced tuff masonry show a wall texture (Figure 10) characterised by roughly squared tuff stones with a regular shape and with thick mortar joints of about $3 \mathrm{~cm}$. Stone dimensions are $16 \times 23 \mathrm{~cm}$ alternated with $20 \mathrm{~cm} \times 20 \mathrm{~cm}$ stones. The levels higher than $40 \mathrm{~m}$ are characterised by an octagonal planimetric layout with walls covered by red and yellow clay bricks (Figure 11) and which probably also forms the internal texture.

\section{Damage relief in structural elements}

Damage was defined by surveying deformations, cracks and visual degradation of materials. Deformations of the frame at the fifth level, at about $41.4 \mathrm{~m}$ where the crosssection becomes octagonal and the walls are made by clay bricks, were observed. The 


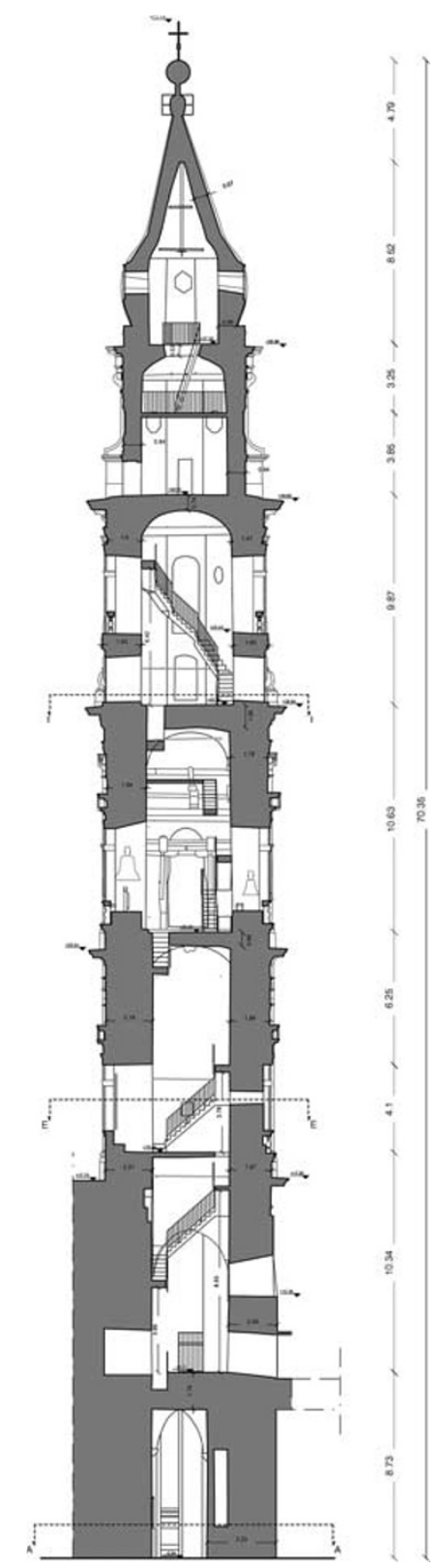

Figure 5: Longitudinal section

analysis of effective conditions was complicated by the various interventions, not always documented, that altered the original configuration of the Tower.

Inspection of the archives of the local historical and architectonical heritage superintendence revealed that the structure had been damaged several times by seismic events in 1656, 1728, 1745, 1762, 1866, 1877 and most recently during the 1980 earthquake. The evaluation of the actual crack distribution, however, did not suggest particular damages to the structures. On the contrary, identification and analysis of the various interventions and alterations carried out over the years, and particularly during the last century, suggested some weaknesses in the global behaviour of the structure. 


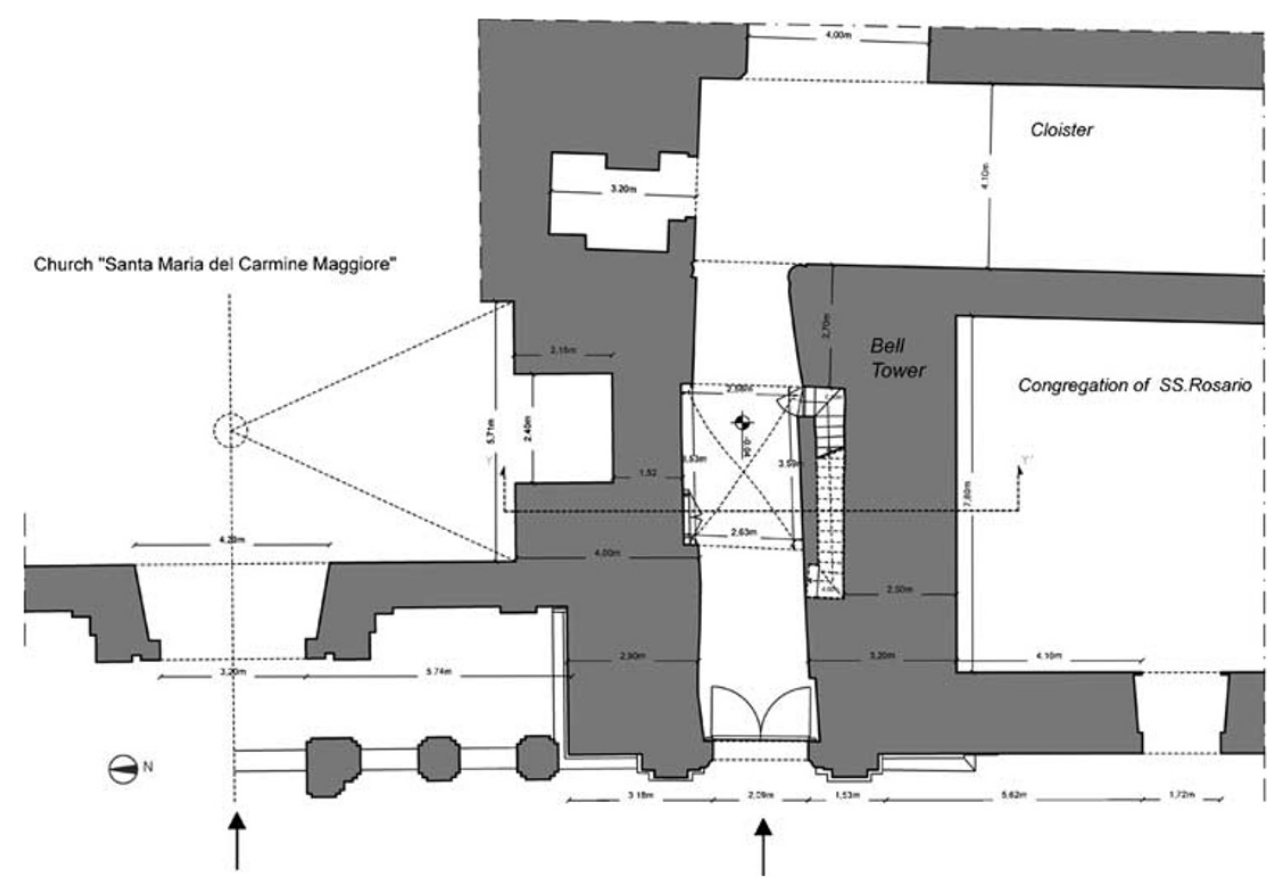

Figure 6: Plan view at ground floor $(+0.0 \mathrm{~m})$

Bibliographical investigation showed that the Bell Tower was accessible only from the first level of the convent, but subsequently (probably in the 1950s) to allow access from the cloister, stairs were added adjacent to the original outside peperino wall of the Bell Tower. At the same time, RC stairs were added to allow repair of the upper levels following the damage sustained during World War II and circled the internal surface of the Tower as shown in Figure 12. The stairs are made of an RC slab well inserted into the masonry (thickness $25 \mathrm{~cm}$ ), as shown by the surface material survey, and has several steel reinforced inclined injections, which improve the connection of the stairs to the masonry walls. Furthermore, the RC stairs have a stiffening effect on the highest and narrowest part of the Tower.

More recent interventions in the 1970s and 1980s consisted of adding extra steel supporting chains and bars to the existing ones, some of which in the upper levels date back to the end of the 19th century, while the strands and the bars through the stairs (Figure 13a) were added in the 1920s and 1930s before the construction of the RC stairs 20 years later. For the strands, only the anchoring plates are visible from the outside (Figure 13b) since the cables run through the walls, while the steel bars (diameter $30-50 \mathrm{~mm}$ ) are visible from the inside of the Bell Tower and whose anchoring systems are generally made of external vertical or semi-horizontal bars (Figure 13c).

During the 1970s, several internal steel chains were added and RC injections were conducted in numerous areas corresponding particularly to the connections of the RC stairs in the masonry walls and in the corners. After the earthquake of 1980, mortar injections, reinforced with steel bars, were realised in the corners of most floors under the fourth level to improve the connections between walls and to improve the monolithic behaviour of the whole structure. These interventions are documented in the archives of the local superintendence as mandatory due to the increasing risk of 


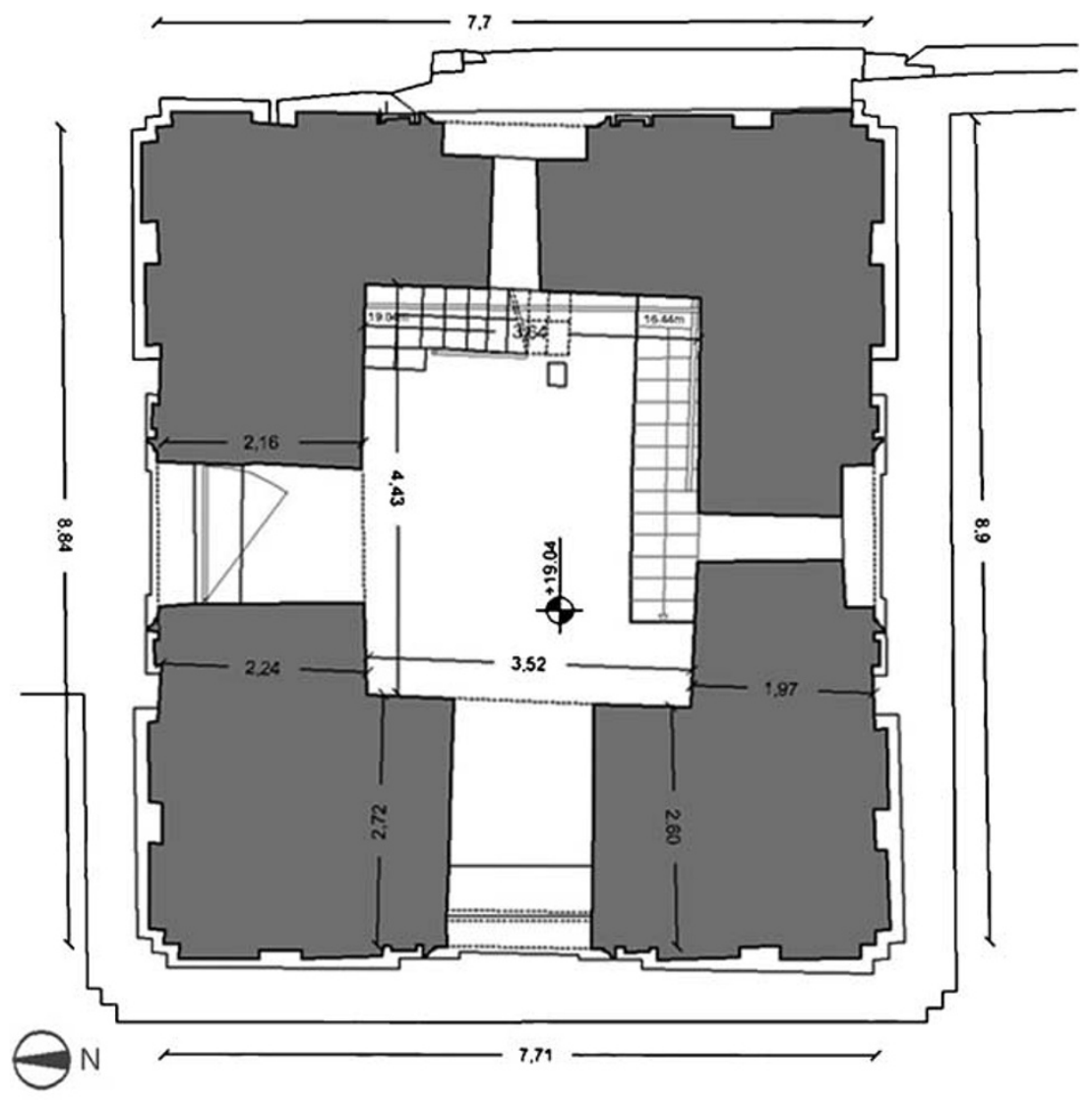

Figure 7: Plan view at $+19.0 \mathrm{~m}$

damage from earthquakes and are simply classified as 'highest urgency' interventions but without any documented record of the actual damage that had occurred. Visual assessment of corrosion of the reinforcing steel strands and bars, which is worsened by proximity of the Tower to the sea, suggests that these previous interventions are no longer fully effective. This suggestion is reinforced with evidence that the upper levels of the Tower are more deformable and is confirmed by the fact that at the upper levels, beyond $40 \mathrm{~m}$, where the Tower is octagonal and slender, some openings have been filled in by tuff curtains (Figure 14) to try to improve stiffness. At the fifth floor $(+41.4 \mathrm{~m}$ level $)$, cracks were identified at the interfaces between new and old materials (tuff/clay bricks) where the original openings have been closed.

The materials used for the floors of the six storeys now vary. In some cases the original wooden floor or masonry vaults were partially removed and modified, probably for structural and functional reasons; at the third level the floor is totally made by an RC slab, while at the other levels RC slabs were fixed on the original vaults (Figure 15). Partial remains of the 15th century vault are visible at level $+13.2 \mathrm{~m}$ (Figure 16) and a wooden beam truss is still present at the level of bells. In most cases the thickness of lateral masonry walls were increased by tuff or concrete addition (Figure 15). 


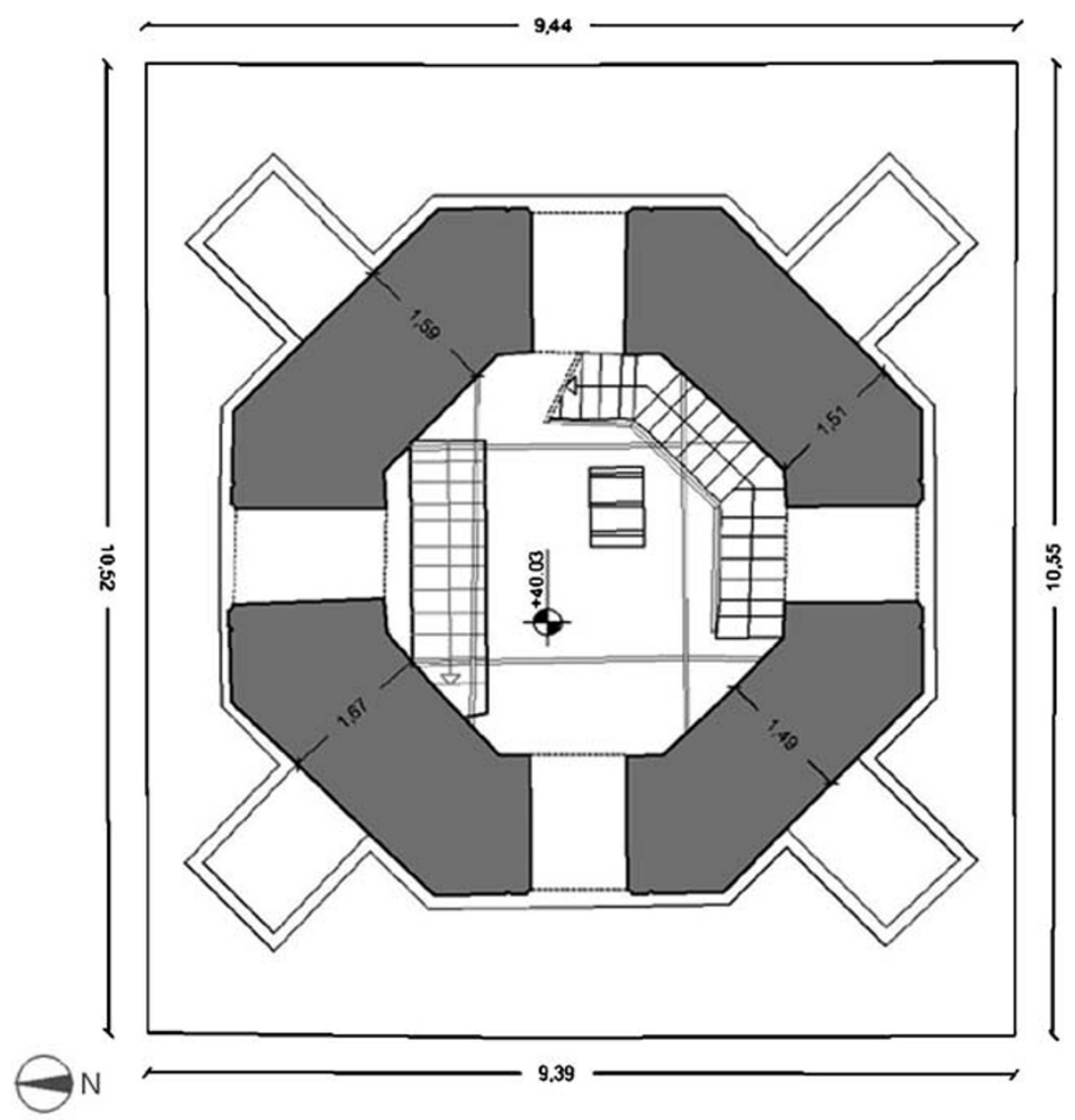

Figure 8: Plan view at $+40.0 \mathrm{~m}$

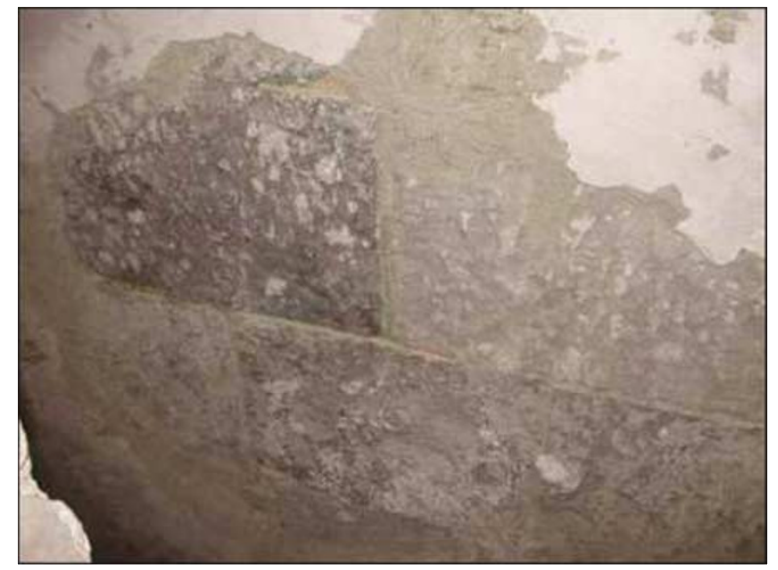

Figure 9: Peperino cover stones

\section{In situ experimental tests to evaluate mechanical properties of materials}

The assessment of the safety conditions of a structure and the design of a reinforcement intervention strategy for static and dynamic loads requires an in-depth knowledge of the 


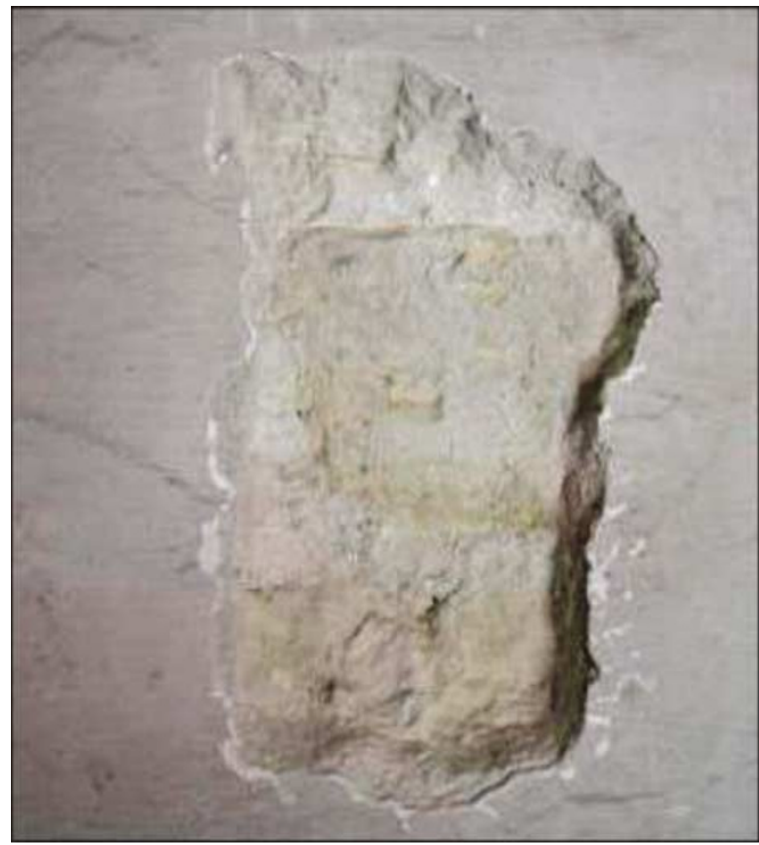

Figure 10: Tuff wall texture

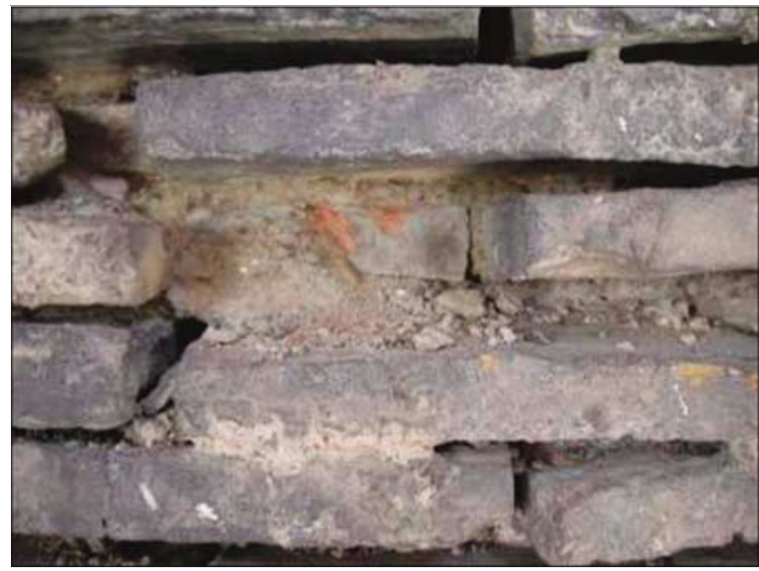

Figure I I: Clay bricks wall texture

actual conditions of the structure. This was more complicated for the Carmine Bell Tower due to the different interventions previously conducted at different times and with different techniques and materials (steel, $\mathrm{RC}$ ) from the original ones, and because of the interactions with the adjacent structures (Church of the Carmine and the Congregation). Tests to evaluate the mechanical properties of the materials and imaging with television probes within the walls allowed the determination of wall thickness, texture and distinguishing coverings. 

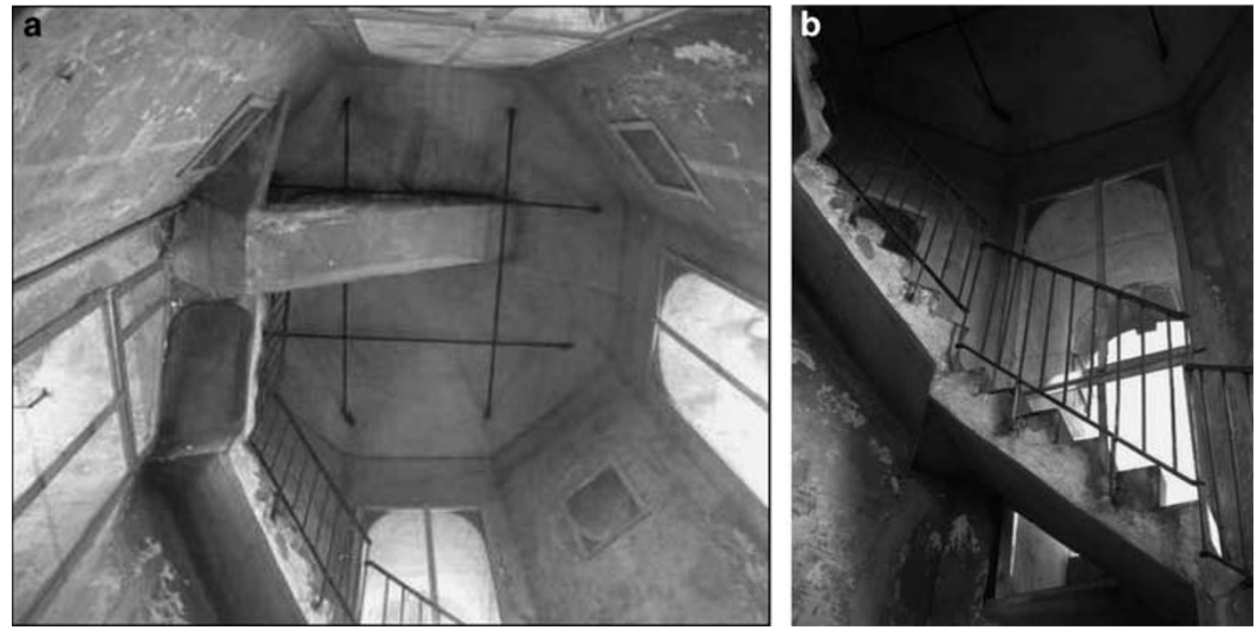

Figure 1 2: (a-b) View of the RC stairs
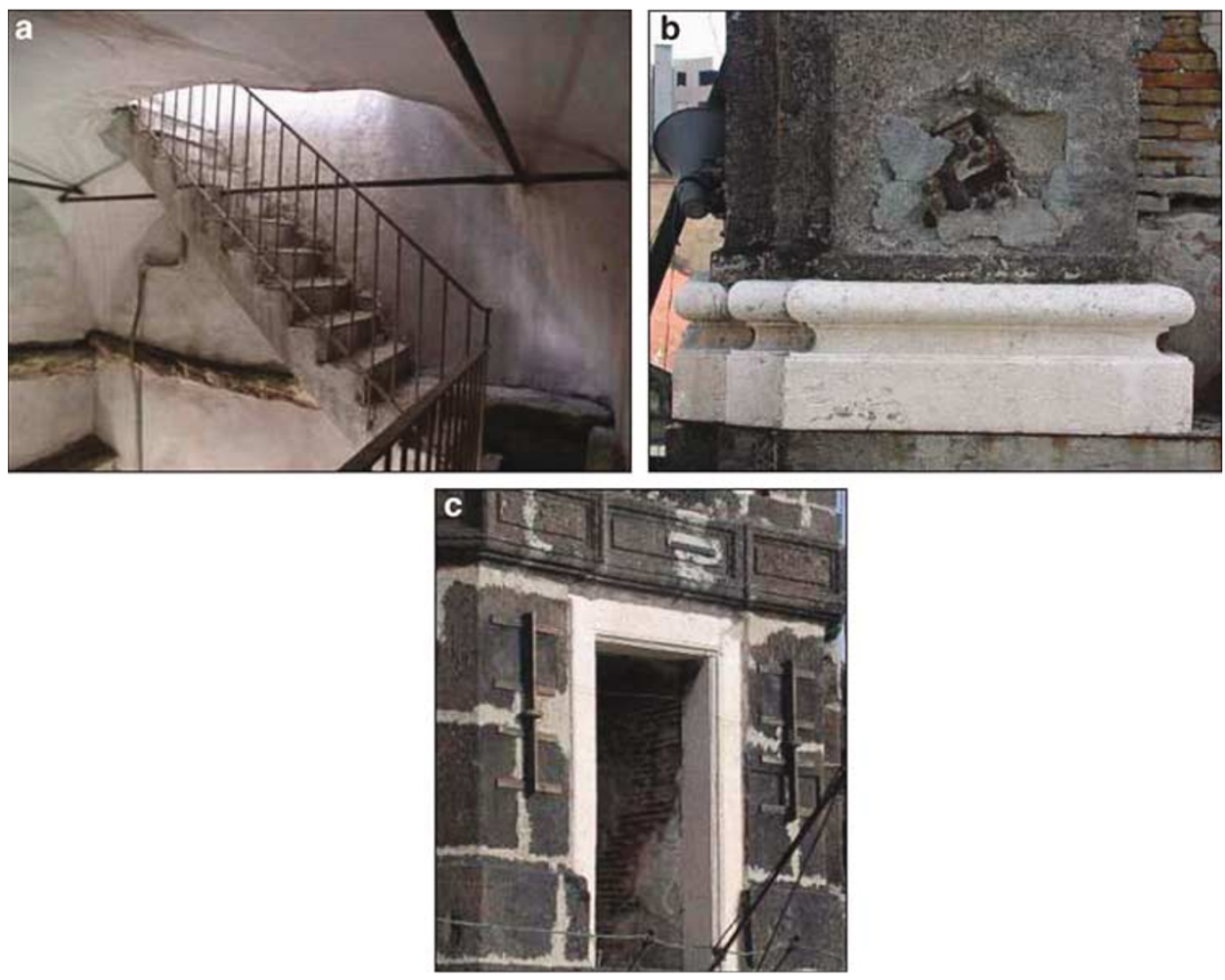

Figure 13: Particulars of chains (a) chains passing in the RC stairs; (b) anchorage of strand and (c) anchorage of bars

Following the in situ surveys and the preliminary assessment of the structure condition, a detailed experimental test programme was planned to accomplish the structural, geometrical and mechanical characterisation of the Bell Tower. In particular, the 

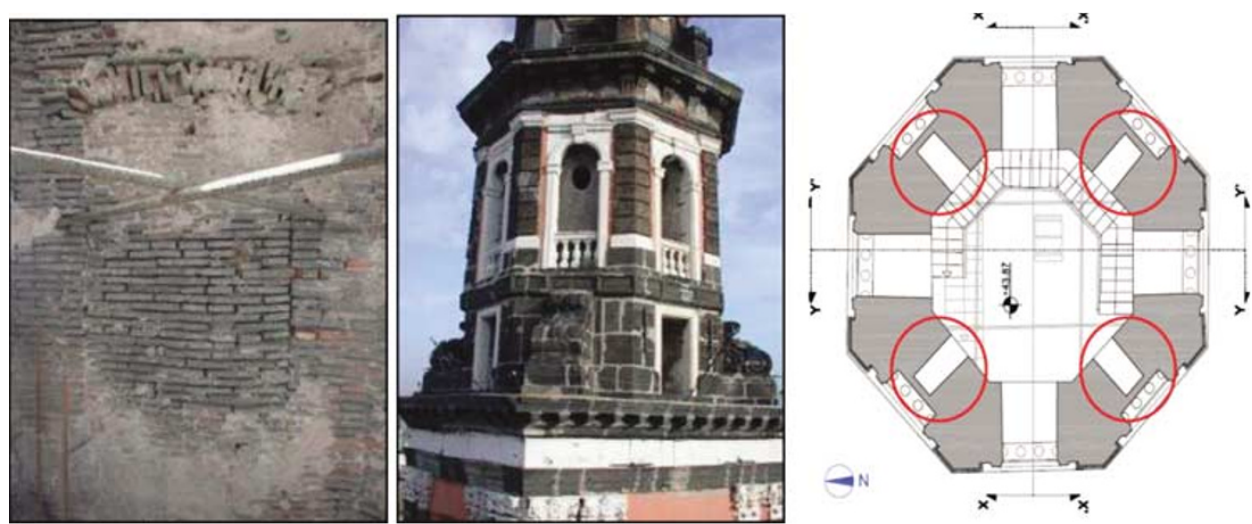

Figure 14: Inside and outside view of closed openings

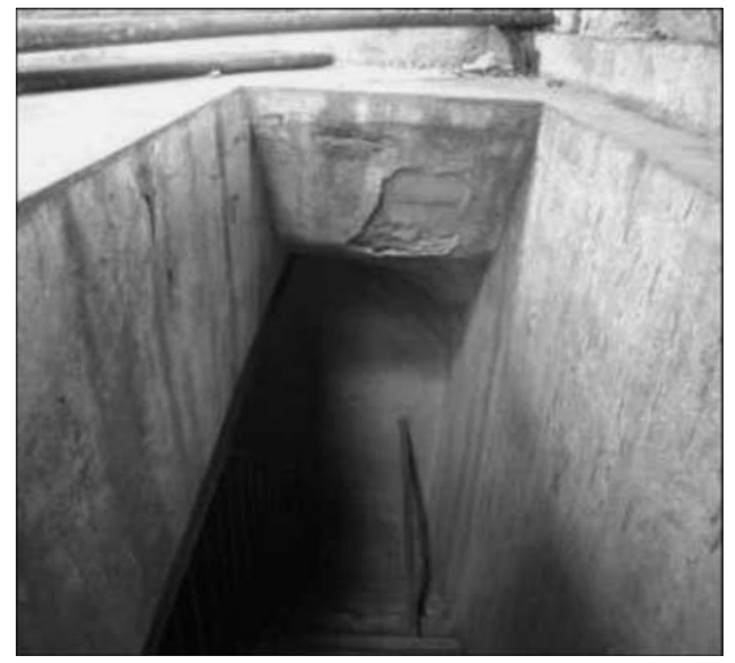

Figure I5: RC slab

following tests were planned and a small number of destructive tests and a larger number of nondestructive tests were utilised in order to evaluate qualitatively the homogeneity of the materials inside the structure:

- Cylindrical samples (diameter 40,60 and $100 \mathrm{~mm}$ ) were extracted from the walls to identify the materials and the wall typology.

- Sonic testing with ultrasound to evaluate the homogeneity of the materials qualitatively and to determine the modulus of elasticity quantitatively.

- Stratigraphical recognition of the wall thicknesses through television imaging.

- Double flat-jacks to evaluate the compressive strength of the masonry and the modulus of elasticity through the definition of the constitutive law of the investigated portions of material. The test is carried out by inserting two flat jacks into parallel slots along the height of the wall. Pressure is applied and gradually increased including uniform compressive stress in the masonry assembly between the jacks. The test is carried out 


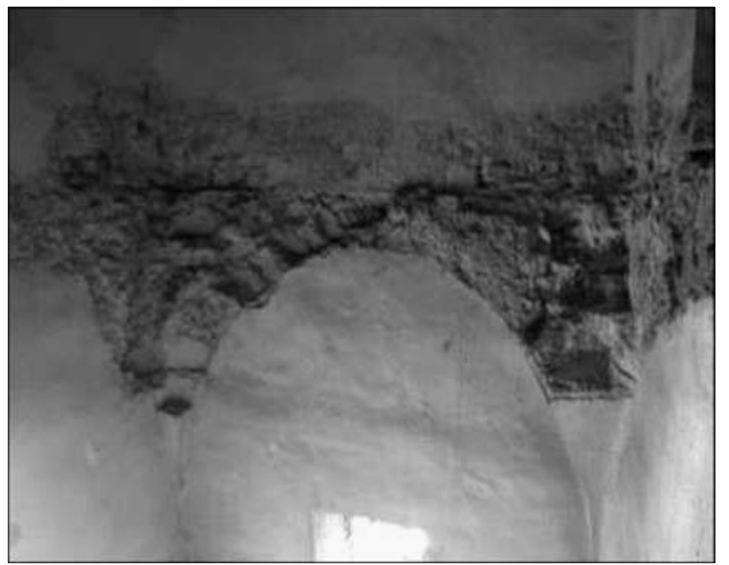

Figure 16: Remains of the demolished vault

until local failure of the masonry occurs and allows defining the compressive strength of the investigated portion and the stress-strain relationship by relieving the variation of distance during the test between fixed reference points.

\section{Destructive tests}

Based on the geometrical survey and the preliminary material survey, 15 samples with diameter $60 \mathrm{~mm}$ were taken out at different levels. The position and extension of the samples accomplished at two levels (indicated as ' $C$ ') are reported in Figure 17. Visual scanning was also accomplished with a video camera through the holes realised in the walls to extract the specimens.

The extracted samples confirmed that the Tower is made of faced tuff masonry walls up to $+41.40 \mathrm{~m}$. The filling material between the two faced tuff walls is made of mortar prepared with pozzolana (another type of volcanic ash) and tuff bricks. Above $41.40 \mathrm{~m}$, the walls are made of clay bricks for the entire thickness except for where the original symmetrical openings have been closed with tuff curtains covered by a layer of clay bricks as described previously. Joint mortars were also made by a mixture with pozzolana. Based on samples extracted at different points, the mean density of tuff and clay bricks were estimated as 15 and $17 \mathrm{kN} / \mathrm{m}^{3}$, respectively. The compressive strength of the tuff was evaluated on cylindrical samples to be about $2.6 \mathrm{MPa}$, a value in the range of variability as described in the literature (Dell'Erba, 1923). Experimental tests on specimens of a similar yellow Neapolitan tuff (Ceroni et al., 2004) gave a compressive strength of $3.7 \mathrm{MPa}$ and a secant Young modulus of about $1800 \mathrm{MPa}$.

The specimen extracted along the northern wall of the Bell Tower bordering the church gave more details on the connection between the two structures, because it evidenced the presence of a peperino stone with a thickness of $20 \mathrm{~cm}$ at a distance of about $90 \mathrm{~cm}$ from the wall surface. This confirms that originally the church and the Bell Tower were separated: in fact the finding of a layer of peperino on the opposite side of the wall suggests that originally this side was open to view and consequently lined with a covering. 
a

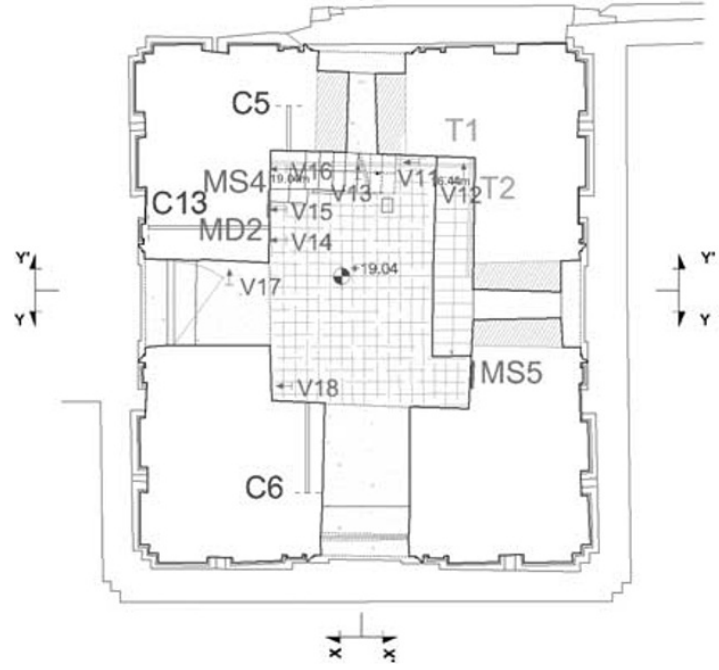

b

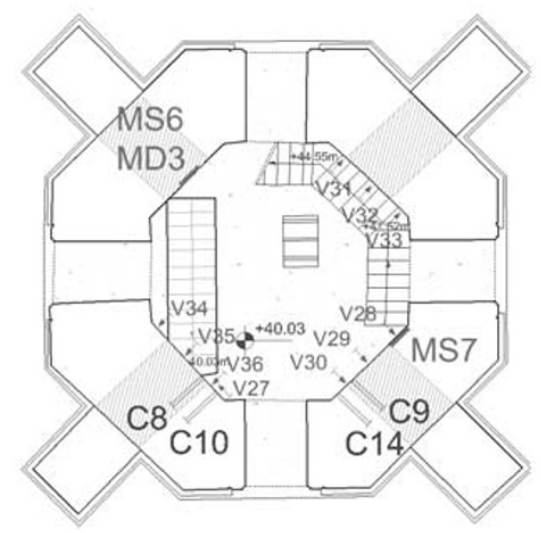

Figure 17: Location of in situ tests (a) plan $+19.00 \mathrm{~m}$ and (b) plan $+40.00 \mathrm{~m}$

\section{Nondestructive tests}

Double flat-jacks. The double flat-jack test allows determination of the constitutive law and compressive strength of the masonry portion investigated (dimensions about $40 \times 50 \mathrm{~cm}$ for a depth of $26 \mathrm{~cm}$ ). In the initial linear range of the constitutive law, that can be assumed with good accuracy between 0 and $1 / 3$ of the compressive strength and as such the elastic modulus can be evaluated.

Three double flat-jack tests were performed in correspondence with three single flat-jack tests (at 8.7, 19 and $40 \mathrm{~m}$ ), the location of two of which are shown as 'MD' in Figure 17. A typical stress-strain relationship obtained by double flat-jack tests is reported in Figure 18 for the faced tuff masonry until the occurrence of local failure happened. The compressive strength given by the three double flat-jacks is reported in Table 2, together with the elastic modulus E, and is calculated on the basis of the stressstrain relationship as secant modulus between 0 and a stress equal to $1 / 3$ of the strength. The elastic modulus given by the flat-jack MD2 was anomalous, probably because it was taken from a nonhomogeneous masonry section while the flat-jack test at MD3 gave a value of elastic modulus similar to tuff, which was expected as the test was performed on a tuff curtain closing an original opening of the clay brick wall.

Since the test takes into account all of the component materials (strength and quality of mortar and stones) and texture (thickness of mortar, dimension and disposition of blocks, connections between the two faces of the wall and the typology of filling materials between faces), the mechanical properties are lower than that for the stone alone. Also the deformability of the stone-mortar assembly can be influenced by the mechanical properties of the single materials, the geometry of the assembly (thickness and texture of mortar layers and dimensions and position of blocks), microcracks and slipping at the interface, which might explain why the elastic modulus of tuff masonry is lower than the one evaluated for single tuff blocks (Ceroni et al., 2004).

Therefore, it has to be underlined that both single materials and masonry assemblies could have been subjected in the past to a damage process due to loading over long 

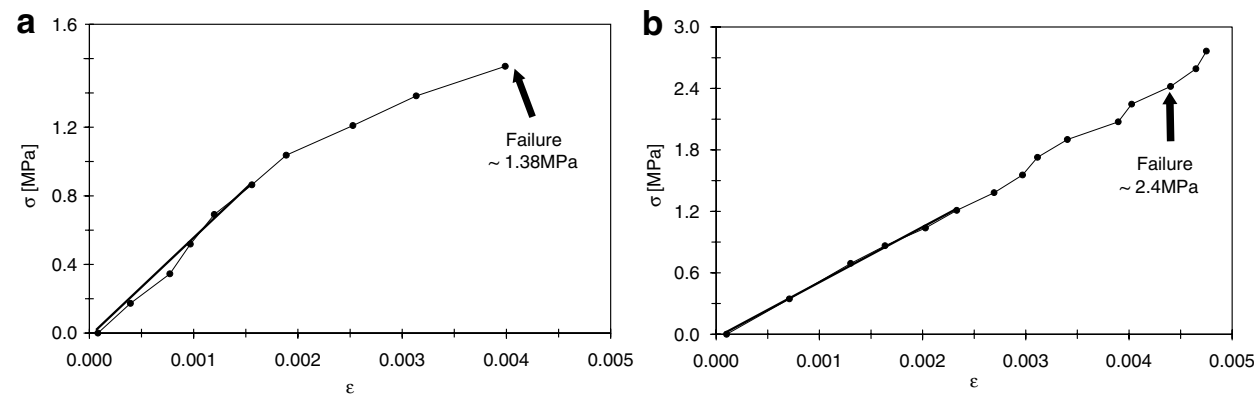

Figure 18: Stress-strain relationship (a) faced tuff (MDI) and (b) clay bricks/tuff (MD3)

Table 2: Results of double flat-jacks

\begin{tabular}{lllll}
\hline & Level & Material & $\mathbf{f}_{\mathrm{m}}(\mathbf{M p a})$ & $\mathbf{E}(\mathbf{M p a})$ \\
\hline MDI & $8.70 \mathrm{~m}$ & Tuff & 1.38 & 530 \\
MD2 & $19.0 \mathrm{~m}$ & Tuff & 1.56 & 340 \\
MD3 & $40.0 \mathrm{~m}$ & Clay brick-Tuff & 2.40 & 530 \\
\hline
\end{tabular}

periods of time or environmental effects (wind erosion, chlorine attack from being near the sea and acid attack from air/traffic pollution), which could have caused a decrease of the original mechanical properties.

Sonic testing. Sonic tests were conducted by transmission of sound waves based on the principle that the longitudinal speed of waves in a continuous body is directly proportional to its elastic modulus according to:

$$
V_{L}=\left[\frac{E_{d}}{\rho} \cdot \frac{1-v}{(1+v) \cdot(1-2 \cdot v)}\right]^{\frac{1}{2}}
$$

Therefore, by knowing the density and Poisson's ratio ( $\rho$ and $v$, respectively) of the investigated material, the dynamic elastic modulus can be evaluated. Measurements were performed by direct, indirect and semi-direct transmission, according to the positions of the source and receiving points (on the opposite sides of the wall, on the same surface of the investigated wall or on adjacent, often orthogonal, walls). When waves intersect a discontinuity (micro-cracks, voids and change of materials), the distance between the source and the receiver increases with respect to the geometric one because the wave avoids the discontinuity so that the speed reduces. About 60 measurements were performed in different points of the Tower with an instrumented hammer. Some examples of wave source location with the corresponding transmission directions are indicated as $V$ in Figure 17.

Using the values of density measured for the stones, for the dynamic elastic modulus the mean values $E_{\mathrm{m}}$, the standard deviation $\sigma_{\mathrm{E}}$ and the covariance coefficient on all the measurements were obtained and are reported in Table 3 together with the local values 
calculated at the same points where the double flat-jacks (MD1, MD2 and MD3) were tested. Values in parenthesis are the number of measurements taken for each material. The values given by the two types of tests are in very good agreement: at point MD1 (tuff, $+8.7 \mathrm{~m}$ ) it is $555 \mathrm{vs} 530$ and at point MD2 (tuff) it is 341 vs 340 , thus proving the nonhomogeneity of the masonry at this level $(+19 \mathrm{~m})$. Measurements of the tuff at different levels gave a mean value (527) with reasonable scatter and similar to the local measures of flat jacks.

Because clay bricks were in some cases substituted by tuff curtains for levels up to $41.4 \mathrm{~m}$, the elastic modulus was variable depending on the points where the waves were transmitted with values higher for clay bricks walls and more similar to tuff where the walls were re-assembled. In fact, the point MD3 was realised in correspondence with a closed opening and the results of both tests (486 for sonic testing vs 530 for flat jack) are values typical of tuff while higher values have been obtained (about $850 \mathrm{MPa}$ ) in correspondence with effective clay brick masonry. In some cases, higher measurements of wave speed are related to the reinforced mortar injections through the masonry walls or to the covering or decorative stones of piperno.

In general the sonic testing has shown homogeneity of values where walls are made with clay bricks, while a greater variability has been discovered in correspondence with faced tuff masonry caused by irregularity and nonhomogeneity of filling materials and masonry assembly, the presence of coverings, injections and steel chains.

\section{Evaluation of stress distribution in materials}

Experimental stresses in situ were tested to evaluate the stress distribution in the masonry by single flat-jacks and to measure the strain in the steel chains.

\section{Single flat-jacks}

The single flat-jack test allows measurement of the compressive stresses in a masonry portion by using a thin flat-jack device installed in a saw cut realised in a mortar joint of the investigated wall. Due to the cut, the local compressive stress of the masonry becomes zero, and the thickness of the slot and the distance between previously fixed reference points reduce. The internal pressure of the flat jack inserted into the slot is progressively increased until the distance between the reference points returns to the original one: the applied pressure corresponds to the in situ original stress of the masonry, unless a shape factor depending on the dimension of flat jack. Results fit the hypothesis of the linear elastic behaviour of materials and can be assumed with good accuracy if the stress level is not high (ie only service loading). Eight single flat-jack tests were performed at four levels $(0,8.7,19$ and $40 \mathrm{~m})$ on opposite walls to test asymmetry in stress distribution. These levels were chosen by considering the variation of materials and plans and were based on the previous geometrical and material surveys.

Table 3: Results of sonic testing

\begin{tabular}{|c|c|c|c|c|c|c|}
\hline \multirow[t]{3}{*}{ Material } & \multicolumn{6}{|c|}{ Elastic modulus (Mpa) } \\
\hline & \multirow[t]{2}{*}{$E_{m}$} & \multirow[t]{2}{*}{$\sigma_{\mathrm{E}}$} & \multirow[t]{2}{*}{ Cov. } & \multicolumn{3}{|c|}{ Local measures } \\
\hline & & & & MD1 & MD2 & MD3 \\
\hline Tuff & $527(16)$ & 87 & 0.17 & 555 & 341 & 486 \\
\hline Clay brick & $852(19)$ & 129 & 0.15 & - & - & - \\
\hline
\end{tabular}


A summary of the results of flat-jack testing is shown in Table 4 and it shows a good uniformity of the stress distribution with a progressive reduction along the height. The flat-jack MS8 was not very accurate because it was taken at a very discontinuous portion of masonry at a dividing wall between the Tower and the Church where the individuation of the perimeter of the two structures was not clear.

These tests provide that the maximum stresses are registered at the base of the Tower, which is linked to the progressive reduction of the wall thickness along the height. Considering the results of the single and double flat-jacks, the vertical stresses are lower than 25 per cent of the compressive strength, showing that for the permanent vertical loads the Tower appears to be safe. The experimental stresses calculated in situ can be directly compared with the results of numerical static analyses developed in hypothesis of the linear-elastic behaviour of materials.

\section{Measurement of strain in steel chains}

Considering the corrosion of some steel chains, tests were performed by measuring the strain levels of the steel by vibration sources in order to evaluate their effectiveness. Twenty-two chains were monitored by strain measurement and they showed that most of them bear tensile stresses varying between 27 and $99 \mathrm{MPa}$, and that eight of the chains are practically unloaded. Some chains have evident problems of corrosion, which, in some cases, has lead to a local failure of the anchorage (Figure 19).

\section{Dynamic tests}

A dynamic characterisation of the structure was performed using environmental sources of vibration from passing traffic, wind and from the ringing bells over a period of three days while extra vibrations were also produced by localised impulses from an instrumented impact hammer. Several mono-axial accelerometers were positioned at different heights (levels 2-7; Figure 4) according to various measurement schemes. Sensors were fixed in the corners at the floor level to check eventual asymmetric behaviours of these nodes and the dynamic characterisation was performed in different steps.

First, acquisition for about $12 \mathrm{~h}$ was conducted by monitoring at levels 4 and 6 with pairs of sensors in the corners in order to have information about the first five modal shapes and evidence asymmetrical behaviour. In a second step, levels 6 and 3 were tested to check anomalies of this floor, which is the last level restrained by the surrounding buildings. In a third step, for about two days, the entire Tower was monitored by using pairs of sensors at each level (from two to seven with the exception of level 5) to have a representation of the model shapes. Finally, the same disposition of instruments has been used by adding another pair of sensors at level 5 and in the basement.

Table 4: Experimental stresses given by single flat-jacks

\begin{tabular}{llll}
\hline Flat jacks & Level & Material & Experimental stress (Mpa) \\
\hline MSI & $8.70 \mathrm{~m}$ (first level) & Tuff & 0.35 \\
MS2 & $8.70 \mathrm{~m}$ (first level) & Tuff & 0.30 \\
MS3 & $0.0 \mathrm{~m}$ (entrance) & Tuff & 0.35 \\
MS4 & $19.0 \mathrm{~m}$ (second level) & Tuff & 0.26 \\
MS5 & $19.0 \mathrm{~m}$ (second level) & Tuff & 0.26 \\
MS6 & $40.0 \mathrm{~m}$ (fourth level) & Clay bricks & 0.17 \\
MS7 & $40.0 \mathrm{~m}$ (fourth level) & Clay bricks & 0.17 \\
\hline
\end{tabular}


In Table 5 the experimental values of frequencies $f$, periods $T$ and damping $D$, of the first five modal shapes, are reported. The first four modal shapes are flexural along the two principal axes of the structure ( $x$-axis North-South; $y$-axis East-West), while the fifth is torsional. For the first and the third modal shapes, displacement happened along the $x$-axis, while for the second and fourth modal shapes displacement was along the $y$-axis. The modal shapes along the two directions seem to be uncoupled and have similar values of frequencies.

In Figure 20, the first four modal shapes of the Tower in terms of acceleration normalised with respect to the maximum that was measured in the Tower ( 7 th level at $57 \mathrm{~m}$ ) are depicted. For each direction the first and second modal shapes show no change of curvature along the Tower, while for the 3rd and 4th modal shapes there is a point of curvature inversion. All the shapes are similar to the dynamic behaviour of a cantilever.

The analysis of the modal shapes in terms of displacement also shows that the first two modal shapes are predominant with respect to the following ones. The three-day data acquisition showed a greater degree of deformability along the $x$ direction (axis North-South) except for the third level of the Tower, which is partially influenced by the surrounding buildings. Mean values of displacement increase at higher levels as shown in Figure 21, where the distribution of mean displacements was recorded over three minutes and is due to the continuative action of wind and traffic. The three-day data acquisition showed an increase in acceleration at peak traffic hours (09.00-12.00am and 05.00$08.00 \mathrm{pm}$ ) along the adjacent main street.

Relevant peaks were also recorded when the bells rang (for 2-3 min with different intensity according to the hours), and although the effects were strongest on the level where bells are positioned (fourth level, $+30 \mathrm{~m}$ ) and on the adjacent ones, a global effect on the entire Tower was however observed. In Figure 22, the maximum displacements registered when bells rang is reported for three time intervals at the six monitored levels. The maximum effect was observed when bells rang at $06.00 \mathrm{pm}$ and the displacement at the bell level had increased by about 35 times compared to normal conditions.

A variation in the frequency responses was registered when bells rang. Peaks of acceleration were observed at a range of frequencies that were different from the natural ones and can probably be explained by the forced oscillations due to movement of bells or of their supports. When bells stopped moving, some peaks corresponding to the natural frequencies of the Tower became discernible again and when bells completely stopped moving, the residual effects were registered at the natural frequencies.

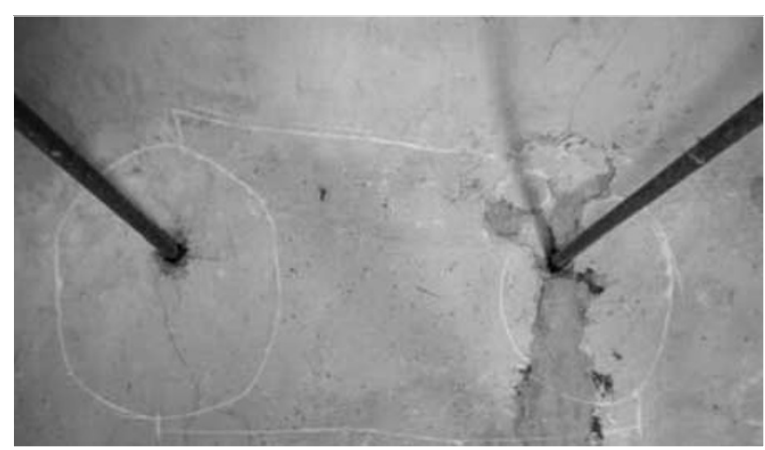

Figure 19: Damage of anchorage of steel chain 
Ceroni, Pecce and Voto

Table 5: Dynamic characterisation

\begin{tabular}{lllll}
\hline Mode & Type & $\boldsymbol{f ( h z )}$ & $\boldsymbol{T ( s )}$ & $\boldsymbol{D}(\%)$ \\
\hline 1 & Flex. $X$ & 0.69 & 1.45 & 1.0 \\
2 & Flex. Y & 0.76 & 1.32 & 1.2 \\
3 & Flex. $X$ & 2.28 & 0.44 & 1.7 \\
4 & Flex.Y & 2.35 & 0.43 & 1.9 \\
5 & Torsional & 2.76 & 0.36 & 1.1 \\
\hline
\end{tabular}

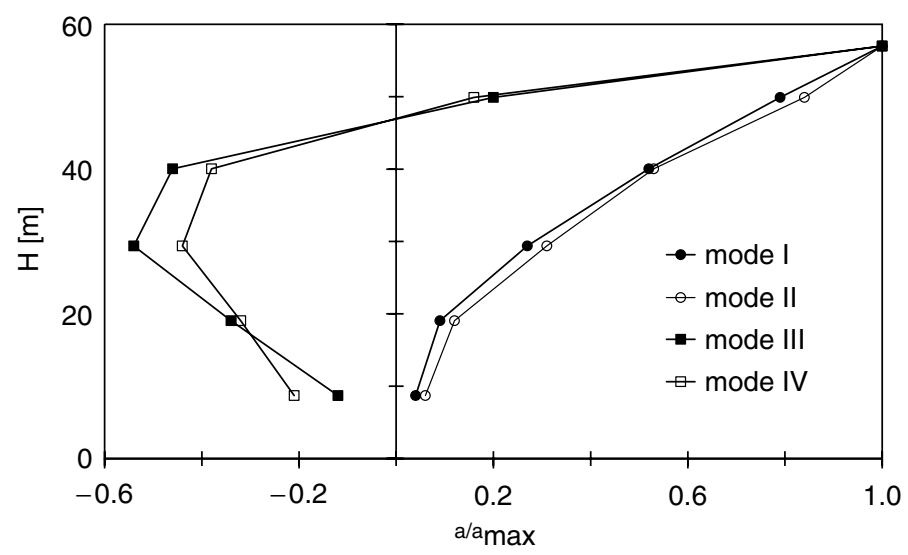

Figure 20: Experimental normalised modal shapes

\section{FIRST SIMPLE ANALYTICAL MODEL}

Results of various tests and research suggest that the Tower was originally built separately from the other buildings and particularly from the church. Therefore, a small restraining effect due to the other buildings on the modal shapes in the $x$ direction (more significant than in the $y$ direction where only some floors of the cloister could have a restraining effect) can be observed for a low dynamic source.

Based on the detailed geometrical relief of the Bell Tower, a 3D finite element model of the structure has been constructed with the commercial software SAP2000 version 9.0 (Computers and Structures, Inc., Berkeley, CA, USA), which considered the Tower as a one-dimensional element with variable sections (four sections have been introduced along the entire height) according to the cantilever scheme (Figure 23).

As the experimental values of density have been obtained by samples made only from tuff and clay bricks, lower values of $12 \mathrm{kN} / \mathrm{m}^{3}$ until the first floor (about $+9 \mathrm{~m}$ ) and $11 \mathrm{kN} / \mathrm{m}^{3}$ for the higher levels for the tuff have been assumed, while $16 \mathrm{kN} / \mathrm{m}^{3}$ has been used for clay bricks. These lower values have been established to take into account the presence of voids, mortar and filling materials in the masonry assembly, especially for tuff masonry. Therefore the density of tuff has been considered higher for the lower levels to take into account the presence of covering in piperno for the basement. The compressive strength of masonry assembly has been assumed to be equal to $1.4 \mathrm{MPa}$ for tuff and 2.4 MPa for clay bricks according to the indications of the double flat-jack testing (Table 2). For tensile strength, a lack of experimental data meant that an assumption had to be made from the literature, so a value equal to 5 per cent of the compressive strength was used (Augenti, 2004). For the linear elastic branch of the constitutive law, the same elastic 


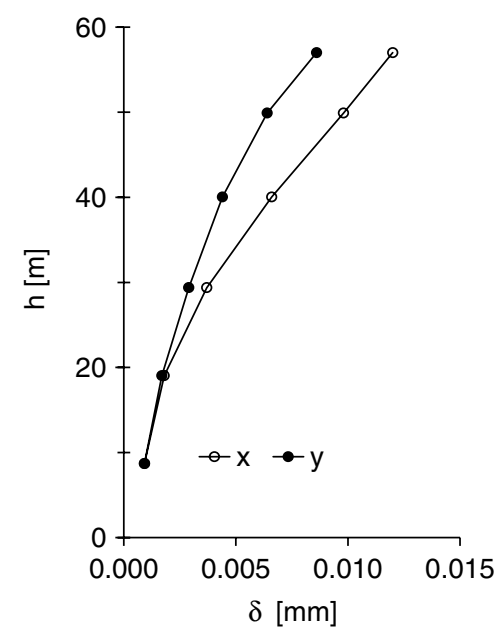

Figure 21: Distribution of mean displacement

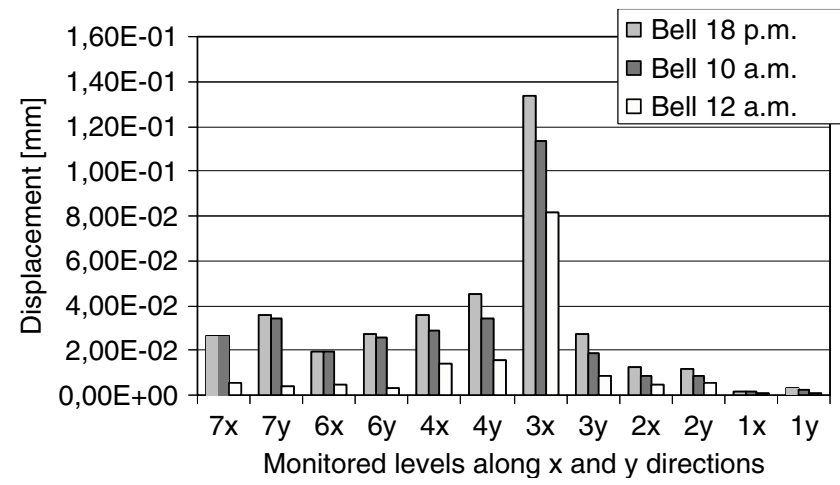

Figure 22: Effects of bells at various levels for different hours during the day (10.00am, I2.00am and 06.00pm)

modulus has been used for compressive and tensile loading adopting an isotropic behaviour. Values of 900 and $1200 \mathrm{MPa}$ have been used for the elastic modulus, respectively, for tuff and clay bricks and were assumed to be greater than the experimental results to simulate a global stiffening effect due to the use of stone coverings, RC stairs, reinforced mortar injections, steel chains, heavy decorative elements at the higher and slender levels and uncertainness about the geometry configuration and the connections with lateral buildings for the first $19 \mathrm{~m}$ of the Tower (corresponding to the original basement).

\section{Linear analysis for vertical loads}

First, a linear analysis of the structure under vertical loads only was performed which assumed that there was no effect of surrounding structures so that the Tower was only fixed in the basement. The experimental normal stresses $\sigma$, obtained by the single flat-jacks, are compared in Table 6 with the theoretical ones given by the model.

Generally, the theoretical values overestimated the experimental values at the lower levels 


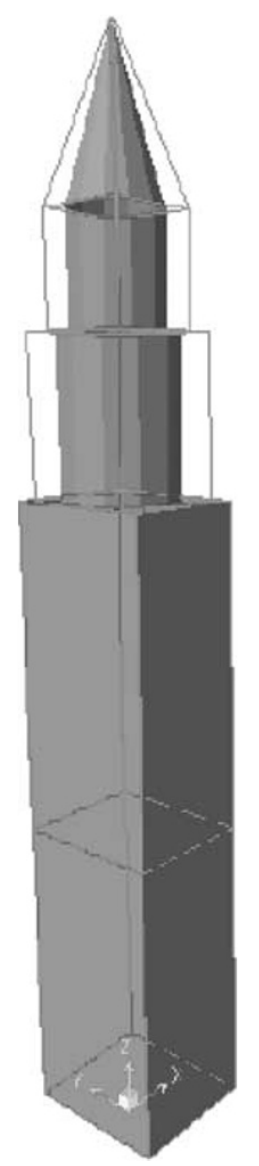

Figure 23: Modelling of the Tower by SAP 2000

by between 15 and 30 per cent but were fairly accurate at the levels made by clay bricks. Numerical analysis revealed that the maximum stress in the tuff bricks was about 30 per cent of the compressive strength and was 7 per cent in clay bricks, confirming the results of the experimental and in situ surveys that the Tower is safe for vertical static loads.

\section{Linear dynamic analysis}

A dynamic modal analysis of the Tower was developed by the 3D finite element model previously described assuming a linear elastic behaviour for all materials. The Tower was modelled according to two configurations, one as described before, where the influence of surrounding buildings was ignored (configuration A (cantilever)), and the other that took into account the effects of the adjacent buildings (configuration B (restrained)) for the first $19 \mathrm{~m}$ of the Tower, which corresponds to the last level that could be constrained by the surrounding buildings. In this second configuration, the effect of contiguous buildings was simulated by horizontal supports in the $x$ direction for the sides of the Tower confined by the church and the fraternity and in $y$ direction for the side confined by the convent/ cloister.

In Table 7, frequencies $f$, periods $T$ and mass participation ratio $\rho$ corresponding to the first four vibration modes are reported for the described boundary conditions and show that the values of period increase when the structure becomes more deformable (configuration A). The torsional modal shape, identified as the fifth mode by the 
experimental dynamic analysis, has not been explained by the modelling because the beam element used has no torsional stiffness. The first four flexural modes, however, cover the majority of the mass of the structure, about 72 per cent for the restrained configuration and 80 per cent for the cantilever scheme.

In Figure 24, the deformation modal shapes corresponding to the first four modal shapes for both configurations are compared with the experimental ones. The comparisons between experimental and numerical results show that in terms of values of natural frequencies the behaviour of the Tower is proximal to the fixed restrained configuration, while the experimental modal shapes are very similar to the behaviour of a cantilever reproduced by configuration $\mathrm{A}$.

In conclusion, the experimental modal shapes show negligible effects of the lateral buildings for the low dynamic action produced by the environmental sources, even if the values of frequencies lead to a hypothesis of a stiffer behaviour of the Tower with respect to the cantilever scheme. When a strong dynamic action occurs, such as during an earthquake, the effectiveness of these kind of restraints is probably reduced and the Tower behaves more like an isolated element particularly as the buildings were originally unconnected.

Analysis of the structure for a combination of vertical permanent loads and horizontal seismic actions, as evaluated with the Italian national code (OCPM 3431, 2005), showed that the maximum stresses in materials overcame the linear elastic limit. Nonlinear analysis must be performed to evaluate the real safety condition of the structure. Furthermore, the risk of local mechanisms due to noneffective connection of masonry walls at the corners points out the necessity to perform local verifications by rigid mechanism models assuming that the masonry panels behave as single brick elements. Both the nonlinear analysis of the global structure and the local verifications are now in progress.

Table 6: Comparison between experimental and theoretical normal stress

\begin{tabular}{lllll}
\hline Flat jack & Level & Material & $\begin{array}{l}\text { Experimental } \\
\sigma(\mathbf{M p a})\end{array}$ & $\begin{array}{l}\text { SAP } \\
\boldsymbol{\sigma}(\mathbf{M p a})\end{array}$ \\
\hline MSI & $8.70 \mathrm{~m}$ (first level) & Tuff & 0.35 & 0.40 \\
MS2 & $8.70 \mathrm{~m}$ (first level) & Tuff & 0.30 & 0.40 \\
MS3 & $0.0 \mathrm{~m}$ (entrance) & Tuff & 0.35 & 0.51 \\
MS4 & $19.0 \mathrm{~m}$ (second level) & Tuff & 0.26 & 0.31 \\
MS5 & $19.0 \mathrm{~m}$ (second level) & Tuff & 0.26 & 0.31 \\
MS6 & $40.0 \mathrm{~m}$ (fourth level) & Clay bricks & 0.17 & 0.17 \\
MS7 & $40.0 \mathrm{~m}$ (fourth level) & Clay bricks & 0.17 & 0.15 \\
\hline
\end{tabular}

Table 7: Dynamic characterisation of Tower by the elastic linear model

\begin{tabular}{|c|c|c|c|c|c|c|c|c|c|}
\hline \multirow[t]{3}{*}{ Mode } & \multirow[t]{3}{*}{ Typology } & \multicolumn{8}{|c|}{ Experimental results Numerical FEM analysis } \\
\hline & & \multirow[b]{2}{*}{$f(\mathrm{hz})$} & \multirow[b]{2}{*}{$T(\mathrm{~s})$} & \multicolumn{3}{|c|}{ Fixed restrain (B) } & \multicolumn{3}{|c|}{ Fixed restrain (B) } \\
\hline & & & & $\overline{f(h z)}$ & $T(\mathbf{s})$ & $\rho(\%)$ & $\overline{f(h z)}$ & $T(\mathbf{s})$ & $\rho(\%)$ \\
\hline I & Flex. $X$ & 0.69 & 1.45 & 0.62 & 2.12 & 0.52 & 0.47 & 1.61 & 0.62 \\
\hline 2 & Flex. Y & 0.76 & 1.32 & 0.71 & 1.82 & 0.52 & 0.55 & 1.4 & 0.62 \\
\hline 3 & Flex. $X$ & 2.28 & 0.44 & 2.63 & 0.5 & 0.20 & 2.00 & 0.38 & 0.18 \\
\hline 4 & Flex. Y & 2.35 & 0.43 & 2.70 & 0.46 & 0.18 & 2.17 & 0.37 & 0.17 \\
\hline 5 & Torsional & 2.76 & 0.36 & - & - & - & - & - & - \\
\hline
\end{tabular}




\section{GENERALISATION OF ANALYSIS PROCEDURE AND FUTURE OUTCOMES}

This study underlines that for a rehabilitation plan for an ancient and/or historical building, various competences are needed. Historical research, geometrical and material surveys, damage assessment and in situ tests have to be developed in parallel to individuate the local and global structural behaviour for static and dynamic actions. Therefore the activities developed in this work suggest a typical procedure to approach the analysis of monumental buildings under several points of view, independently from the location and extendible to masonry structures made by different materials.

For the examined case of the Bell Tower of Santa Maria del Carmine, the analyses was very complex because of the complicated geometry, the variety of materials, the presence of past modifications and restoration interventions as well as for the structural effects of surrounding structures, but all of these data were needed in order to develop a reliable model of the structural behaviour of the Tower. The results of in situ tests and the linear static analysis performed by a simple finite element model showed that the Tower is under a low level of stress for vertical loads. The experimental dynamic behaviour of the Tower has been compared with the results of the numerical linear dynamic analysis and showed minor effects of surrounding buildings in the presence of environmental dynamic sources. A nonlinear static analysis is in progress assuming a nonlinear behaviour for materials to evaluate the displacement capacity of the Tower that will be compared with the design displacement demand evaluated according to national seismic codes. Furthermore, studies about the effectiveness of connections between walls are in progress to consider the reliability of out-of-plane local failure mechanisms, which should be avoided by improving the monolithic behaviour of the Tower by substituting or adding new chains.
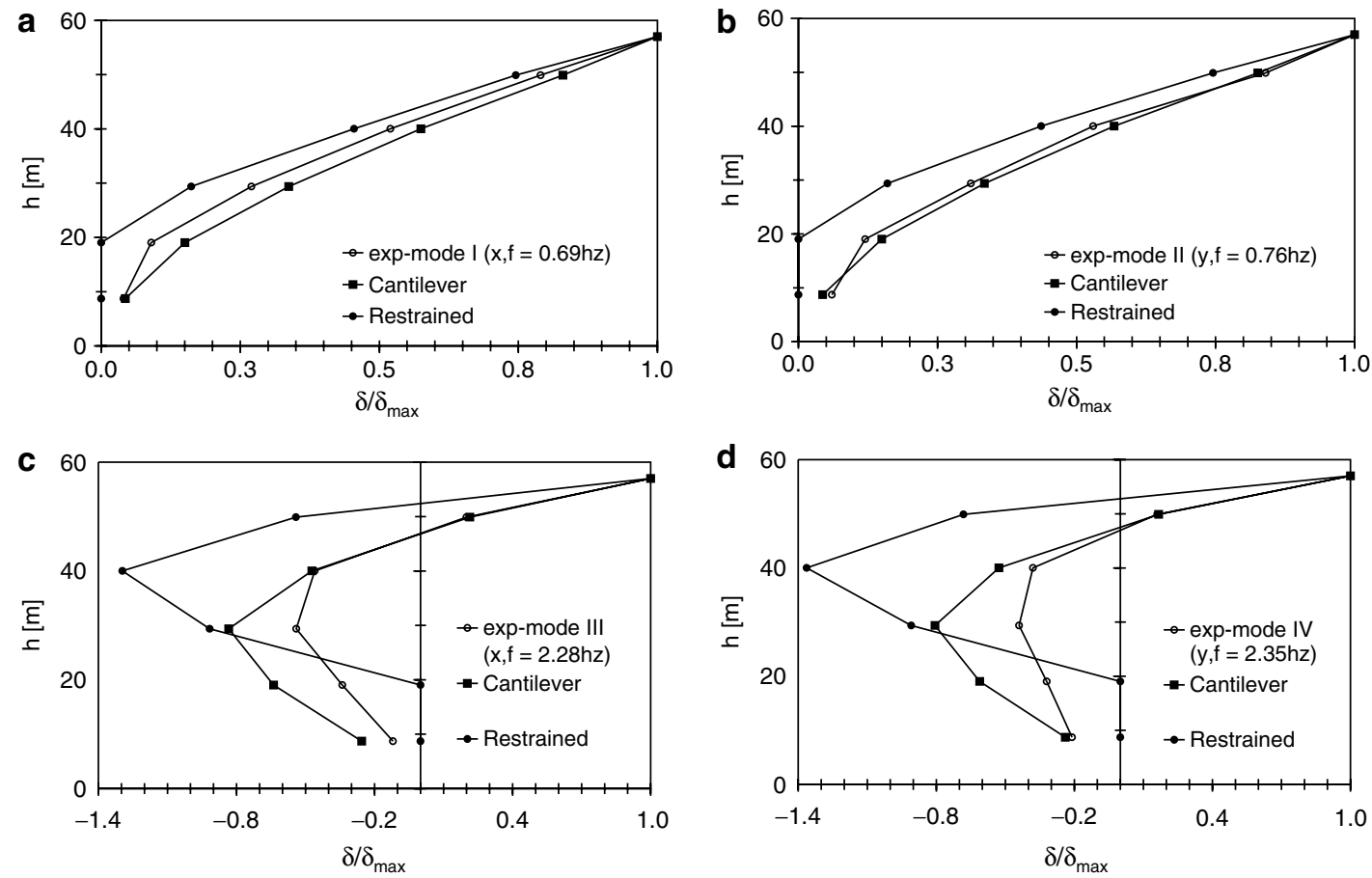

Figure 24: Modal shape for several configurations: (a) Mode I; (b) Mode II; (c) Mode III and (d) Mode IV 


\section{Acknowledgements}

Activities on the Bell Tower of Santa Maria del Carmine have been developed within the project P.O.N. TE.M.P.E.S with the collaboration of the Architectural Heritage Authority of Campania. The authors acknowledge TECNOIN S.R.L and STRAGO S.R.L. for the experimental tests in situ.

\section{References}

Augenti, N. (2004) 'Il calcolo sismico degli edifici in muratura', Editor Utet Università, ISBN: 8877509422 (in Italian).

Binda, L, Saisi, A and Tiraboschi, C. (2000) 'Investigation procedures for the diagnosis of historic masonries', Construction and Building Materials, 14, 199-233.

Carpinteri, A. and Bocca, P. (1991) 'Damage and diagnosis of materials and structures', Proceedings of DDMS 91, Politecnico di Torino, Bologna: Pitagora.

Celano, C. and Chiarini, G.B. (1974) 'Notizie del bello, dell'antico e del curioso della città di Napoli, divise dall' autore in dieci giornate per guida e comodo de' viaggiatori, con aggiunzioni di Giovan Battista Chiarini', Napoli, Edizioni Scientifiche Italiane.

Ceroni, F., Pecce, M., Manfredi, G., Marcari, G. and Voto, S. (2004) Analisi e caratterizzazione meccanica di murature di tufo, $15^{\circ}$ congresso CTE, Novembre, Bari, pp. 905-914, (in Italian).

Dell'Erba, L. (1923) 'Il tufo giallo napoletano. Studio scientifico e tecnico esteso alle cave e alle frane', Ed. Pironti, Napoli.

Filangieri, G. (1885) 'Chiesa e Convento del Carmine Maggiore in Napoli, Descrizione storica e artistica', Tipografia dell'Accademia Reale delle Scienze, Napoli 1885, Bibl. Naz. Sez. Nap. Misc. IX B 2.

Moscarella, P.T. (1589-1825) 'Chronistoria del Carmine Maggiore di Napoli', written by Pier Tommaso Moscarella until 1589 and continued by Alii until 1825, Bibl. Naz. Sez. Misc.X AA2.

OCPM 3431, Ordinanza del Presidente del Consiglio dei ministri (2005) Primi elementi in materia di criteri generali per la classificazione sismica del territorio nazionale e di normative tecniche per le costruzioni in zona sismica, Document no.3431 (in Italian).

Quagliarella, P.T. and Guida storico-artistica del Carmine Maggiore, Napoli, Taranto (1932) Bibl. Naz. Sez.Nap. VIB 1026. 